\title{
TEMAS EMERGENTES
}

\author{
Precariedades en la Academia \\ Precarity in Academia \\ (coordinado por Marta Pérez y Ainhoa Montoya)
}

\author{
$* \quad * \quad *$

\section{La insostenibilidad de la Universidad pública neoliberal: hacia una etnografía de la precariedad en la Academia}
The Unsustainability of the Neoliberal Public University: Towards an Ethnography of Precarity in Academia

\author{
Marta Pérez ${ }^{1}$ \\ Universidad Complutense de Madrid \\ Ainhoa Montoya ${ }^{2}$ \\ University of London
}

\section{RESUMEN}

Partiendo de una preocupación por la Universidad, que cada vez más se sostiene sobre contratos precarios, apuntamos posibles aspectos a abordar en futuros análisis de la precariedad en la academia, especialmente de sus dimensiones más invisibles, aquellas que se concretan en prácticas neoliberales a las que nos adherimos en nuestro quehacer cotidiano y que (nos) vulnerabilizan a la par que convierten el trabajo en la academia en una labor individual y de competición. Al hacerlo, pretendemos encontrar otro imaginario de la labor académica, y de la Universidad, que recupere lo público como proyecto común a la vez que se interrogue sobre su naturaleza.

Palabras clave: Academia; Precariedad; Neoliberalismo; Universidad; Etnografía.

\footnotetext{
${ }^{1}$ Correo electrónico: martap27@ucm.es. ORCID iD: <https://orcid.org/0000-0003-3269-7773>.

${ }^{2}$ Correo electrónico: ainhoa.montoya@london.ac.uk. ORCID iD: <https://orcid.org/0000-00017052-4318>.
} 


\section{SUMMARY}

Spurred by our concern for the university institution and its increasing dependence on unstable employment contracts, we present possible approaches for future analyses of precarity in the academic world. We emphasise the most invisible aspects of precarity that materialise in the neoliberal practices to which we adhere in our daily lives. Such practices render us-and academia-vulnerable, while transforming academic work into an individual and competitive endeavour. Our goal is to seek other imaginaries for both academia and the university institution, reclaiming its public quality as a common project and questioning its nature.

Keywords: Academia; Precarity; Neoliberalism; Public University; Ethnography.

Comenzamos a pensar este número en el verano de 2016, tras varias charlas compartidas sobre la producción de conocimiento en la academia y fuera de ella. Una de nosotras vive en Londres y trabaja como profesora e investigadora en una Universidad mientras que la otra está en Madrid, por aquel entonces en paro, implicada en un proyecto de investigación militante y en búsqueda de empleo como profesora, algo que conseguiría en 2017. A pesar de las diferencias en contexto académico y en situación laboral, compartimos reflexiones en torno a qué tipo de etnografía y qué tipo de docencia se pueden hacer desde una Universidad cada vez más preocupada por medir el impacto de las investigaciones y la calidad de sus profesores ${ }^{3}$; una Universidad que sigue sin demoler la torre de marfil académica al tiempo que se sostiene en gran medida sobre la proliferación de contratos temporales y sobre una implicación del personal académico en general que va más allá de la jornada completa, el despacho y el aula (Gregg, en Castillo y Moré 2017: 8).

Nos asaltan las dudas acerca del futuro de una Universidad que, de diversa forma según los contextos, establece criterios de valoración de las investigaciones que coadyuvan con los intereses del mundo empresarial y de la gestión de servicios públicos pero no valora cuánto contribuyen a la transformación social; una Universidad que configura la docencia cada vez más como una actividad que resulta una carga, si bien es alrededor de la cual surgió la institución universitaria, y constituye, a medida que se reduce la financiación pública y de formas particulares según los contextos, un pilar económico fundamental para la misma. Una Universidad que, de nuevo de forma diferencial según los contextos, incorpora los procedimientos de evaluación de méritos de las académicas de maneras que, sin conducir necesariamente a una mejor rendición de cuentas, perpetúan la precariedad ya existente o generan sus propias formas de precariedad. Aún así, a las dos, desde nuestros respectivos lugares, nos empuja el deseo de formar parte de esta Universidad que avanza en su producción de una precariedad que atraviesa nuestros cuerpos y nuestras formas de conducirnos. $\mathrm{Y}$ es que trabajar en la Universidad nos permite disfrutar de las satisfacciones que obtenemos de preparar y participar en las clases, de compartir procesos de investigación con estudiantes, compañeros, y personas con las que trabajamos, de pensar, de leer y de escribir.

Las preguntas sobre esta aparente paradoja han articulado la sección que aquí in-

\footnotetext{
${ }^{3}$ Con respecto al género, por razones tanto de concisión como de visibilización, empleamos indistintamente el masculino y el femenino para referirnos a los y las académicas.
} 
troducimos. En ella, y para dar cuenta de las tensiones y ambigüedades que constituyen la precariedad como aquí la entendemos, echamos mano de las tres dimensiones de lo precario que propone la filósofa Isabell Lorey $(2016)^{4}$. La primera, la condición precaria, remite — siguiendo a Judith Butler - a la vulnerabilidad de los cuerpos, a la interdependencia con respecto a otros cuerpos. La segunda, la precariedad, alude a los procesos de jerarquización social de esos cuerpos a través de los mecanismos de alterización, esto es, a la desigualdad social. Por último, la tercera dimensión de lo precario es identificada por Lorey como la precarización como gubernamentalidad neoliberal, una generosa distribución de libertad entre los sujetos — sustitutiva de la protección social welfarista- que les impele a gestionar sus propios riesgos y que tiene como efecto el gobierno de lo social a través de la inseguridad (tanto material como subjetiva).

Así, al reflexionar sobre la precariedad en esta sección establecemos relaciones entre estas tres dimensiones. Con respecto a la condición precaria, la dificultad para que la Universidad como institución reconozca la interdependencia de los cuerpos, sobre todo en procesos de cuidado intensivo como puede ser la maternidad, se materializa en unas expectativas de rendimiento sin pausa en la carrera académica imposibles de cumplir para una madre y muy difíciles para quienes no cuentan con redes de apoyo. En relación a la precariedad, la jerarquización que estructura la Universidad implica una relación entre contratos y estatus social y simbólico que es fundamental para la reproducción de posiciones precarias sobre las que se sostienen otras más estables (ver los textos de Touhouliotis y Téllez para datos al respecto en dos contextos diferentes). Pero también hay una división en estratos que valora más los trabajos intelectuales-separación entre académicos y otros trabajadores de la Universidad-y, dentro de ellos, los procesos de conocimiento que se relacionan con la investigación-la valoración es menor si el conocimiento proviene de las discusiones y el aprendizaje compartido que tienen lugar cada día en la clase con los estudiantes. Finalmente, con respecto a la precarización como gubernamentalidad neoliberal, las fuerzas que nos empujan a individualizar la carrera académica y a poner en el centro de nuestra subjetividad el rendimiento, la acumulación y la competición son claves en nuestro análisis y están presentes en todas las contribuciones a este número, que es en sí mismo un esfuerzo por pensar colectivamente sobre nuestra inseguridad.

Un esfuerzo que hemos llevado a cabo en nuestros ratos libres, pero que ha mantenido su presencia todo este tiempo como una discusión situada, siempre en construcción, dentro de la que pensar nuestras experiencias y las de otras, preguntándonos cómo la etnografía puede contribuir al entendimiento no solo de aquello que estudiamos sino de nosotras mismas, del contexto en el que trabajamos y de nuestras prácticas: las dudas sobre si solicitar algunos de los escasos puestos de investigación que permiten avanzar en la carrera académica o de los más comunes y precarios puestos de docencia que ofrecen una promesa a futuro pero también pueden llegar a estancar o detener la carrera; los planteamientos sobre si cambiar de lugar de residencia incluso desplazándose a otro país para obtener un empleo o quedarse en el lugar de residen-

\footnotetext{
${ }^{4}$ El párrafo que sigue, y que resume las tres dimensiones de la precariedad que propone Lorey, estaba incluido en la primera versión de la contribución de Débora Ávila, Ariadna Ayala y Sergio García para este número. Generosamente, nos lo cedieron para usarlo en esta introducción.
} 
cia aun cuando pueda suponer la precariedad laboral e incluso el desempleo; si trabajar en la educación superior y la investigación formal o fuera de ellas, libres de sus encorsetamientos pero con menos recursos, reconocimiento y legitimidad; si intentar encontrar una estabilidad laboral escasa ya en muchos sectores o continuar aprendiendo a vivir a salto de mata; la alegría por conseguir contratos temporales en la Universidad o becas de investigación, y el cansancio que acompaña a la preparación de múltiples cursos de docencia a la par que la acumulación de méritos de investigación y el cumplimiento de tareas de gestión; la sensación de culpa por llegar siempre muy justas a los plazos y la falta material de tiempo para hacerlo de otra manera; los cuestionamientos ético-políticos sobre qué tipo de investigación hacemos, cómo y para quién, y la búsqueda de formas que nos permitan compartir y colaborar dentro y fuera de la academia sin que esto nos saque fuera del todo, especialmente por el tiempo que requiere y lo poco que se valora; la curiosidad que alienta nuestro disfrute investigando, escribiendo y como docentes y la incómoda y, en muchas ocasiones, insostenible carrera por acumular méritos (sobre todo aquellos que cuentan) para poder seguir investigando, escribiendo y trabajando como profesoras.

Hoy, mientras escribimos estas líneas en el invierno de 2018, ninguna de las dos puede asegurar que seguirá en el mismo puesto de trabajo dentro de seis meses, pero es posible que la situación haya cambiado para cuando se publique este número. Por un lado, en comparación con otras posiciones precarias en las que la incertidumbre afecta de forma más general, descarnada y constante a la supervivencia y en las que, además, no cabe el goce en el trabajo, nosotras somos unas privilegiadas. Por otro, la experiencia de la incertidumbre con respecto al futuro más cercano y la sensación de que el goce va ligado a expectativas — propias y ajenas- insostenibles y en ocasiones contradictorias, las compartimos con cada vez más compañeras en la academia (además de fuera de ella). Es sobre esa incertidumbre y esa insostenibilidad, sobre esa precariedad de los sujetos, sobre la que se asienta la Universidad hoy, y esto es algo que comparten los diversos contextos y culturas académicas, como pretendemos poner de manifiesto en esta sección.

A lo largo de los últimos dos años podemos encontrar algunos ejemplos de relatos sobre la precariedad en la academia en general (Butler, Delaney y Sliwa 2017; Castillo y Moré 2017; Hernández et al. 2010) y en la antropología en particular (AllegraLab 2016; Cultural Anthropology 2018; Muehlebach 2013; Peacock 2016; Thorkelson 2016). Cabe destacar, por otra parte, que la mayoría de ellos se ubican en el ámbito divulgativo: congresos, blogs, foros y artículos en prensa. Además del empeoramiento de las condiciones laborales de quienes trabajamos en la academia - esto es, en investigación y en docencia en universidades y centros de investigación- algunas reflexiones sobre la precariedad han analizado también la relación que existe entre la precarización del trabajo de los y las académicas y las transformaciones en la Universidad como institución educativa (Heatherington y Zerilli 2017), así como con la "precarización de la existencia" que señalaba, hace ya más de una década, el colectivo Precarias a la Deriva (2004).

En esta sección, nos situamos en este esfuerzo por poner en relación esa precarización de la existencia de las académicas con las transformaciones en la institución que les emplea, la Universidad, pensando más allá del contrato o, más bien, situando el contrato como un elemento más de todo un continuum de prácticas y discursos que 
encontramos en las experiencias con los diversos contextos académicos, experiencias que en esta sección abordamos a través de las contribuciones de personas que trabajan o han trabajado en España, Reino Unido, Serbia, varios países de América Latina y Estados Unidos. Como editoras de este "Tema Emergente", pedimos a las autoras relatos personales que reflexionaran sobre su propia experiencia de la precariedad. Los textos de este número constituyen por lo tanto un lugar desde el que empezar a pensar cómo examinar etnográficamente nuestra precariedad como sujetos que habitamos y contribuimos a hacer, a través de nuestras prácticas, la Universidad pública neoliberalizada. Más que el fruto de investigaciones sistemáticas, las contribuciones a esta sección son, de manera más o menos explícita, ejercicios de pensamiento crítico y analítico sobre la propia experiencia, y revelan líneas a investigar en futuras etnografías de la precariedad en la academia.

\section{LO PERSONAL ES POLÍTICO: APUNTES PARA UNA ETNOGRAFÍA DE LA PRECARIE- DAD EN LA ACADEMIA}

En cada uno de esos contextos, la precariedad está conformada por formaciones ideológicas, estructuras jerárquicas y normativas, y formas de trabajar y relacionarse singulares, más o menos gerontocráticas, más o menos endogámicas, más o menos meritocráticas. Como apuntan los textos que conforman este número, es la experiencia situada en un contexto determinado la que nos permite entender la relación entre las formas que toma la precariedad en la vida cotidiana, las maneras que tenemos de incorporarla y los procesos más amplios de funcionamiento y transformación de la Universidad. Por ejemplo, en España la introducción de la práctica de la evaluación en las universidades ha venido acompañada del discurso de la meritocracia, como solución al relato de una Universidad endogámica que no produce investigaciones y que no deja entrar al "talento" (Indocentia 2015).

Abordando esta discusión desde el margen, la pregunta que nos hacemos aquí no es si se producen más o menos investigaciones sino para qué, para quién y atendiendo a las necesidades de quién ${ }^{5}$ y nos planteamos si la meritocracia, entendida como evaluación, puede garantizar acabar con los efectos excluyentes de la endogamia, pues establece criterios guía para las carreras académicas que no todas podemos - $\mathrm{O}$ queremos- seguir por igual. Por ejemplo, la acumulación de méritos valorados por los sistemas de evaluación se concreta en obtener publicaciones en revistas de impacto $^{6}$ o de reconocido prestigio, un requisito que produce sus propias desigualdades: por un lado, no todas las personas pueden cumplirlo al mismo nivel, pues una académica que acaba de ser madre, o una con un contrato temporal de docencia que

\footnotetext{
${ }^{5}$ Es en este punto donde la torre de marfil académica y los criterios de valoración de las investigaciones se encuentran: si la crítica a la primera se basa en que las investigaciones que produce la academia universitaria en ciencias sociales y humanidades son, sobre todo, para garantizar su propia reproducción, la introducción de lo segundo dirige las investigaciones a la búsqueda de una utilidad para el mercado y/o la gestión pública, lo que no tiene por qué coincidir (raras veces lo hace) con las necesidades y los intereses de los sujetos con los que investigamos.

${ }^{6}$ Aquellas revistas incluidas en los índices de medición de revistas científicas, sobre todo en el Journal Citation Report (JCR) y en Scopus.
} 
necesita de otros empleos para sostenerse, no puede dedicar el mismo tiempo a escribir y publicar que sus compañeros con puestos más estables; por otro, una profesora que establezca como prioridad prepararse las clases, o realizar un proceso de review de sus publicaciones con los sujetos que han participado en su investigación, no puede publicar con la misma celeridad que sus compañeros. ¿O deberíamos decir competidores? Porque es en la subjetividad que producen estas prácticas de evaluación donde la precariedad se incorpora: una forma de pensar(nos) que coloca el miedo a perder la carrera como acicate cotidiano en el que el trabajo invade todas las esferas de la vida (Fleming, en Castillo y Moré 2017: 6-7) y que nos devuelve una premisa concreta: "ante todo, no bajarse del tren" (Castillo y Moré 2017: 60).

Varios autores desde diferentes disciplinas - filosofía, antropología, sociología, estudios del trabajo- se han ocupado de reflexionar sobre la relación entre una subjetividad que pone en el centro el rendimiento máximo y las instituciones que le sirven de contexto de producción, en el marco del estudio sobre la neoliberalización de lo público en general (Brown 2015; Laval y Dardot 2013). Con respecto a la Universidad en particular, aunque es una problemática poco investigada en este contexto, cada vez más autoras están escribiendo sobre ello, tal y como ya hemos indicado más arriba. Todas coinciden en señalar una aparente paradoja: la capacidad de los académicos para examinar situaciones precarias en sus investigaciones y en sus clases y la dificultad de que las conversaciones sobre la precariedad en la Universidad vayan más allá de los pasillos y tomen la forma de discusión pública en el seno de la academia (Gill 2010), o incluso de objeto de nuestras investigaciones. La lectura de una contribución de Brian Mckenna (2016) al blog de ética de la American Anthropological Association (AAA Ethics Blog) fue uno de los acicates de esta sección. Mckenna urgía a los y las antropólogas a estudiar y visibilizar the elephant in the room ${ }^{7}$ : el silencio evidente y la falta de examen de nuestras propias experiencias con la precariedad. La antropología ha estudiado de forma extensa a los vulnerables, los pobres, los desencantados. Hemos examinado la precariedad en otros ámbitos, decía Mckenna, pero no estamos viendo que los antropólogos (precarios) se están convirtiendo en el otro. ¿Por qué esa dificultad?

Además del análisis de artículos en medios de comunicación, de nuestras propias experiencias y de conversaciones informales con colegas, para comenzar a reflexionar el tema de este número elaboramos una serie de preguntas que lanzamos a colegas y amigas de diferentes contextos, sobre todo España y Reino Unido, pero también del este de Europa, América Latina y Estados Unidos. No era tanto una forma de buscar una muestra representativa como una manera de intentar entender, de manera exploratoria, cómo los diferentes contextos y culturas académicas están dando forma a la precariedad. Aunque estos colegas ocupan posiciones diversas -laboral, geográfica, social, política y personalmente- en la $\operatorname{academia}^{8}$, sí comparten en

\footnotetext{
${ }^{7}$ Literalmente, el elefante en la habitación, expresión empleada en inglés para denotar algo obvio pero que se evita. Es significativo el título de otro de los artículos más citados con respecto a la precariedad en la academia, y que se menciona más arriba: "Breaking the Silence ['Rompiendo el silencio']", de Rosalind Gill (2010).

${ }^{8}$ Mandamos el cuestionario a quince personas, cuatro de las cuales nos dijeron que no podían responder por tiempo, una respuesta bastante elocuente de su propia condición de preca-
} 
sus respuestas una idea común: la relación tensa con el tiempo, en un empleo que cuenta con el privilegio de tener horarios más flexibles que otras profesiones pero en el que el tiempo de trabajo se extiende claramente más allá de la jornada laboral y hace retroceder a la vida, dificultando el detenerse a pensar en la propia práctica y en la vulnerabilidad que la atraviesa.

La dificultad de mostrar vulnerabilidad fue otro de los problemas sobre los que reflexionamos en el verano de 2017, en un taller en Madrid en el que académicas y no académicas discutimos la relación entre precariedad, diferentes entornos académicos y prácticas de nuestro trabajo, como parte de las actividades del colectivo de investigación y aprendizaje Escuela de Afuera' ${ }^{9}$ Varias y complejas razones explican esta dificultad para visibilizar la vulnerabilidad, entre las que encontramos el miedo a perder el empleo, pero también a ser visto como débil y, en posiciones más estables, a incomodar a los pares con estos problemas y poner en riesgo nuestras relaciones dentro de la academia; la adherencia a prácticas que precarizan pero que son necesarias para construir una carrera y la construcción de otras como precarizantes justamente porque no son (tan) valoradas en esa carrera; y la tensión entre la experiencia de contar con una posición social públicamente privilegiada y el sentido de vulnerabilidad que no se discute y se relega a la esfera privada.

El politólogo Alexander Gallas (2018) en su introducción al número de la revista Global Labour Journal dedicado a la precariedad en la academia, se refiere a las «barreras cognitivas ${ }^{10}$ : habría, señala Gallas citando al sociólogo Tobias Peter, una autodescripción hegemónica del sujeto académico, ligada estrechamente a las culturas de auditoría y evaluación (ver Strathern 2000). Esa autodescripción constituye al sujeto en torno a la pasión, la reputación, el continuo emprendimiento de proyectos y la medición de su rendimiento. Su autoexplotación, de haberla, no es tan interesante como otras que no son "escogidas": el que se queja es que "se ha equivocado de profesión" (Gallas 2018: 73) ${ }^{11}$. Si la queja es la otra cara de la moneda del relato

riedad. De las ocho personas que finalmente respondieron, algunas estaban sin empleo, otras recibían su salario de un empleo fuera de la academia sin dejar de trabajar en la academia, otras tenían contratos a tiempo parcial en la Universidad, otras a tiempo completo pero temporales; algunas son madres, otras han cambiado de lugar de residencia siguiendo empleos con frecuencia y todas ellas tienen diferentes perspectivas sobre la academia y el lugar que les gustaría ocupar en ella. Preguntamos cuánto tiempo dedicaban a diferentes tareas (clases, escribir artículos, escribir solicitudes de financiación y trabajo, hacer revisiones de los artículos de otros, hacer investigación, tareas administrativas, etc.); cuál era el valor que otorgaban a esas tareas y cómo las disfrutaban; cuáles eran sus estrategias para manejar la precariedad y si, en ese manejo, sentían que estaban transfiriendo su precariedad a otras (colegas, estudiantes, investigadores independientes, etc.); preguntamos si encontraban un ángulo positivo a su precariedad y qué tipo de prácticas imaginaban para transformar su situación precaria.

${ }^{9}$ En: <www.escueladeafuera.net>. Fecha de acceso: 25 abr. 2018.

${ }^{10}$ Gallas enumera otros tipos de barreras: las ético-políticas (los estudios del trabajo se interesan históricamente por las clases menos privilegiadas); las político-estratégicas (que fijan el foco en luchas laborales más intensas y visibles); y las barreras económicas (que se concretan en el miedo a perder el empleo o a perder capital social y opciones de relaciones incluso cuando se cuenta con un puesto fijo).

${ }^{11}$ El ensayo titulado El Entusiasmo, de Remedios Zafra (2017), nos sirve para entender cómo esto aplica a otras profesiones vocacionales (creación artística, diseño, etc.). Gracias a Esther Ramón y Javier Gil por remitirnos a este trabajo. 
de la reputación y el emprendimiento, la pregunta que emerge es: ¿cómo crear un espacio en el que se derriben las barreras para la visibilización de la precariedad en la academia pero también se reflexione críticamente sobre nuestra propia adherencia a las prácticas que (nos) precarizan?

Los relatos que componen este número conectan de manera crítica la propia experiencia laboral con otros aspectos de la vida - convivencia con colegas, con parejas, con mascotas, o sentimientos de pertenencia-, con procesos más amplios en el mundo académico —neoliberalización de la Universidad- y con la posible producción de otras subjetividades, formas de sustraerse a prácticas que (nos) precarizan. Son ejercicios en esa forma de "gobernar(nos) de otra manera" que señalaba Michel Foucault (1997) al preguntarse "¿qué es la crítica?", y que profundizaba Judith Butler (2001) en su texto de respuesta al filósofo francés: una crítica que se hace en relación a una forma de conducir(se) y que, en ese ejercicio, abre tanto una distancia con la norma, incluida la norma de reconocimiento de lo que es ser una académica, como la posibilidad de otras conductas. Una crítica que puede enlazar productivamente con perspectivas feministas, que suman a las propuestas anteriores la apuesta por el conocimiento situado (Haraway 1995) y la dimensión colectiva de una práctica de la reflexividad que somete las generalizaciones a la prueba de los relatos encarnados, y que es capaz de producir, en el mismo proceso, teoría y organización para la acción (Malo de Molina 2004).

Como trabajo experimental, estos textos construidos desde lo personal nos sugieren valiosas pistas de hacia dónde pueden ir las investigaciones etnográficas de la precariedad en la academia: la exploración de los espacios más íntimos en los que toma forma y fuerza la precariedad, pero también su intersección con procesos institucionales más amplios tanto en Europa como en América Latina (Hoffman); la reflexión personal sobre el deseo y las dificultades para construir una carrera académica en un espacio central en Europa (Reino Unido) cuando no se tiene un pasaporte británico ni las redes de apoyo necesarias para sostenerse en el proceso (Serbia, Jovanović); el relato etnográfico de cómo la Universidad estadounidense - y los profesionales con puestos más estables dentro de ella- se sostienen sobre una posición institucional y económicamente precaria - la del profesor adjunto- que es no obstante fuente de capital social y simbólico, aunque diferenciado por clase, raza y género (Touhouliotis); el "retrato robot" de una investigadora, profesora y madre que pasa por los estadios precarios del camino hacia la estabilidad propios de la Universidad española, que pone de manifiesto el modo en el que las experiencias al borde de la insostenibilidad se invisibilizan a la vez que se normalizan (Téllez); y el disparador que encuentran tres profesoras de Universidad que, en comparación con otras, no consideran su situación laboral como precaria pero que, cuando se detienen a pensar en la combinación que se da en la academia entre erótica, angustia y agotamiento, encuentran razones para escribir y mostrar cómo esa combinación produce precariedad, de los sujetos y de la Universidad (Ávila, Ayala y García).

\section{PRECARIEDAD COMO INSEGURIDAD Y COMO FORMA DE REGULACIÓN}

La generosidad de las autoras de las contribuciones - por el relato de experiencias tan personales- y su perspectiva crítica, nos permiten vislumbrar que una etno- 
grafía de la precariedad en la academia debe ir más allá del contrato, para rastrear también sus manifestaciones más invisibles: ¿qué significa la precariedad en la academia, teniendo en cuenta que sus trabajadores tienen el grado de formación más alto? ¿Quién vive bajo condiciones precarias y cómo es la experiencia con la precariedad en la Universidad? ¿Es la precariedad el mejor término para describir las experiencias de las personas que trabajan en la academia hoy? ¿Cómo podemos hacer más visible la precariedad y sus ramificaciones en la academia, para nutrir una acción que pueda transformar la actual situación? Sin ignorar que la temporalidad de los contratos en la Universidad es una tendencia que avanza en todos los contextos, estas preguntas nos permiten situar esta tendencia en un proceso más amplio de producción de precariedad que tiene sus singularidades.

Por ejemplo, aunque podemos encontrar similitudes entre las condiciones laborales de los profesores adjuntos en Estados Unidos y de los profesores asociados en España, también existen notables diferencias que dan cuenta de cómo varias lógicas -meritocrática y endogámica- lejos de oponerse, pueden trabajar juntas en la producción de precariedad ${ }^{12}$. En España, como relata Virtudes Téllez, contar con un contrato de profesora asociada suele ser el primer paso para una carrera académica después del doctorado, a pesar de que este tipo de puesto se creó originalmente para contratar a profesionales que trabajan fuera de la Universidad y que dan clases relacionadas con sus campos de experticia. Lo que suponía una actividad extra para estos perfiles es ahora un contrato precario por el que tienen que pasar quienes aspiran a desarrollar una carrera en la Universidad a tiempo completo y que puede llegar a extenderse durante años. En este periodo de aguante, durante el cual la ligazón contractual con la Universidad solo incluye la docencia a tiempo parcial, se constituye una precariedad laboral que se agrava por la particular combinación de endogamia y meritocracia: publicar y asistir a congresos es clave aquí para tener más seguridad en las opciones a una plaza, algo que, como relata Téllez, es muy difícil de compaginar con la crianza de un bebé y con, al menos, un segundo empleo. Sin embargo, no es suficiente; las redes de contactos y apoyos continúan siendo fundamentales incluso para obtener este tipo de contratos precarios, así como para consolidarse.

En Estados Unidos, sin embargo, el puesto de profesor adjunto no juega el papel de puerta de entrada a una institución en concreto, como relata Vasiliki Touhouliotis: la movilidad es muy alta y, después de pasar por un contrato de adjunto, las personas que pueden irse a otra universidad como postdoc o como profesoras lo harán, mientras que otras - las que hicieron su doctorado en universidades no de élite, y/o las que no han entrado en la carrera de las publicaciones porque han de mantenerse con un segundo y hasta un tercer empleo - no pasarán del puesto de adjuntas, una «inclusión diferencial» (Ávila y Malo 2008) que reproduce tendencias endogámicas.

\footnotetext{
${ }^{12}$ Según las culturas académicas de distintos países, las formas de permitir la entrada o el ascenso y consolidación en la academia, así como la distribución de beneficios y privilegios están dominadas por distintas lógicas que con frecuencia coexisten pero de manera distinta según el contexto. Además del texto de Téllez, ver también en este número Ávila, Ayala y García para España y Touhouliotis para Estados Unidos. Ver también Peacock (2016) para Alemania. Tal y como nos señaló un revisor anónimo, esta es una línea fundamental para futuras investigaciones, "el modo en el que coexisten estas lógicas y cómo se expresa en la cotidianidad del sistema docente e investigador esta coexistencia" en distintas culturas académicas.
} 
Inclusión diferencial en la que el género tiene un rol importante. De hecho, no es casual que los relatos de este número tengan como protagonistas a mujeres, a excepción del artículo colectivo que también incluye a un hombre, pues la precariedad que describimos está atravesada de manera notable por desigualdades de género, así como de clase y raza (Touhouliotis). Mientras las autoras que trabajan en España experimentan una incertidumbre laboral relacionada con la dificultad de asegurar un empleo con buenas condiciones, las autoras que trabajan en el contexto anglosajón experimentan esa incertidumbre en la dedicación de una gran parte del tiempo de un empleo a buscar el siguiente.

La movilidad, que ocupa un lugar central en las contribuciones de Hoffman y Jovanović a este número, es tanto el resultado de la precariedad como uno de los procesos que la profundizan. Jovanović nos muestra cómo los requisitos de los regímenes de visado colisionan con los deseos de continuar una carrera en un centro de producción de conocimiento académico como es Reino Unido, engarzando una cadena de movilidades e inmovilidades que exacerban el cansancio, la angustia y la escasez de recursos económicos propios de las situaciones de espera tras obtener el doctorado. Por su parte, Hoffman relata, con ricas descripciones, una movilidad que se extiende en la carrera académica más allá de la primera beca postdoctoral: cómo se relaciona esta movilidad con el amor y con la intimidad, pero también los altos costes de estos desplazamientos cuando se hacen en precario, al tener que desprenderse constantemente de los objetos necesarios para la vida cotidiana y tener que adquirirlos una vez más en cada destino; los esfuerzos para adaptarse con cada desplazamiento no solo a los lugares sino a entornos institucionales diferentes; y la vulnerabilidad que la movilidad produce cuando no se cuenta con una afiliación académica estable y se trabaja como investigadora independiente con contratos precarios de docencia y/o investigación y con intervalos sin afiliación o contrato alguno.

Sin embargo, a pesar de la dureza de algunas situaciones, y tal y como señalan tanto Hoffman como Jovanović, las académicas tendemos a pensar que la situación es transitoria, que no es merecida y que, debido a nuestras habilidades y méritos, podrá cambiar. En este aspecto, son fundamentales las redes de apoyo que nos proporcionan nuestros familiares, nuestras parejas, nuestras amigas y compañeras, o nuestro estatus social. Precisamente el estatus social asociado a la academia es objeto de especial reflexión en este número. En nuestros encuentros con colegas y amigos para reflexionar sobre la precariedad en la academia, hemos tenido siempre presente una pregunta: en comparación con otras personas, amigas que trabajan en tiendas, hostelería o en telemarketing, o que tienen trabajos con largas horas de oficina, ¿cómo nos podemos llamar precarias? Tenemos trabajos que nos permiten viajar, estar en constante contacto con la producción de conocimiento que tanto apreciamos, presentarnos como investigadoras..., en definitiva, cultivar un importante capital social y cultural.

Para responder a la pregunta de si nos podemos considerar precarias, tenemos que explorar las complejas maneras en las que el estatus que confiere la academia se relaciona con la precariedad. Por un lado, como ya señalábamos arriba, produce explicaciones del tipo pobreza elegida, que sitúa la solución a situaciones de precariedad en la academia en el individuo que las sufre. Durante 2017 hemos podido leer relatos de profesores adjuntos en Estados Unidos viviendo situaciones de pobreza, lo que desencadenó discusiones acerca de si los que sufren esas condiciones deberían o no 
abandonar la academia ${ }^{13}$. Sin embargo, el texto de Ávila, Ayala y García nos ayuda a abordar ese debate en otros términos: el de la relación entre el miedo a caer en la carrera - siendo la caída en la pobreza el extremo de un continuum - con el deseo de formar parte del mundo de la Universidad y el cansancio que produce tener que cumplir con todos los requerimientos. Entre ellos, los que tienen que ver con la evaluación, que no sólo toman cada vez más tiempo de otras tareas más importantes, sino que también son un recordatorio constante de la condicionalidad de la carrera, siempre en construcción, nunca del todo segura, y constituida por la necesidad de producir resultados en comparación (y competición) con los pares.

Este tipo de análisis nos ayuda a formularnos otras preguntas. Por ejemplo: ¿a qué aspiramos al desear formar parte de la Universidad? Más que obtener una respuesta definitiva, lo interesante aquí es ver cómo esta pregunta nos obliga a conectar nuestras propias experiencias de la precariedad en la academia con formas de gobierno y poder que están transformando la Universidad, no sólo como nuestra empleadora, sino como institución pública de todos y todas. Una pregunta, pues, que somete las generalizaciones sobre la neoliberalización de la Universidad a la prueba de los relatos encarnados y que nos permite teorizar desde abajo al tiempo que producir intuiciones para la acción. Pero además una pregunta que requiere de análisis etnográfico y que invitamos a pensar en este número.

\section{DES-PRECARIZAR LA UNIVERSIDAD}

Poner sobre la mesa la pregunta sobre qué Universidad deseamos nos permite, en primer lugar, adoptar unas lentes colectivas con respecto al problema de la precariedad. Las soluciones individuales — centrarse en publicar y en intentar sacar algo de tiempo para relajarse, disfrutar de ocio, etc.- si son las únicas, nos devuelven la metáfora que uno de nuestros colegas, el antropólogo y profesor Carlos Diz, nos regaló en su respuesta a nuestras preguntas: la de un púgil cansado, que pelea en la "lona de lo académico", que "para hacer currículum ha de saber tocar el violín con los guantes de boxeo aún calzados", y que en los descansos piensa en cuántos asaltos más podrá aguantar. Esta imagen no sólo nos sirve para mostrar la soledad de las situaciones personales: también nos ayuda a reconocer la vulnerabilidad sobre la que se asienta la sostenibilidad de la Universidad hoy en día, y a sacar a la luz la invisibilización de todo aquello que sostiene la Universidad que no es el homo

${ }^{13}$ Ver, por ejemplo, el artículo publicado en el periódico The Guardian el 28 de septiembre de 2017: "Facing poverty, academics turn to sex work and sleeping in cars" (Disponible en: <https:/ /www.theguardian.com/us-news/2017/sep/28/adjunct-professors-homeless-sex-work-academiapoverty>. Fecha de acceso: 25 abr. 2018) que generó una discusión acerca de si los profesores adjuntos que vivían en esas condiciones debían o no abandonar la Universidad. Para un ejemplo que argumenta sobre la disponibilidad y legitimidad de otras opciones, en concreto con respecto a estudiantes de The New School, ver <https://www.insidehighered.com/views/2017/10/16/whyadjuncts-should-quit-complaining-and-just-quit-essay> (Fecha de acceso: 25 abr. 2018); para una respuesta que argumenta que la suerte de los adjuntos tiene que ver con el deterioro progresivo de la Universidad, ver <https://www.insidehighered.com/blogs/just-visiting/telling-adjuncts-quitgiving-education> (Fecha de acceso: 25 abr. 2018). 
academicus. En la Universidad que llamaremos pública —en cuanto a historia y norma institucional - y neoliberal — por las lógicas de competencia y corporatización que la organizan - la búsqueda personal de seguridad se sostiene sobre la inseguridad de otros, produciendo "cadenas de precariedad" (Pérez y Montoya 2016): profesores más precarios con cuerpos agotados, estudiantes que soportan las subidas de tasas que se adoptan para aumentar ingresos con que sostener universidades cada vez menos subvencionadas con financiación pública; personal externalizado y precarizado hasta niveles que van más allá de los que soporta el personal académico, investigadores independientes que, sin formar parte de las redes de legitimidad y recursos universitarios, aportan conocimiento, contactos y trabajo a las investigaciones oficiales a cambio de contratos también precarios. Desafortunadamente, en la Universidad neoliberal, la obtención de mayor seguridad para algunos corre el riesgo de traducirse en inseguridad para otros si no pensamos la insostenibilidad de la precariedad de la propia institución a la par que la nuestra.

La del púgil que lucha solo y se esfuerza por aguantar asaltos es una imagen que refleja muy bien la pelea individual del académico en la Universidad pública neoliberal; para pensar una lucha colectiva, y otra Universidad pública, tenemos que encontrar una imagen diferente ${ }^{14}$. Pero, ¿por qué necesitamos esa lucha colectiva? ¿Y por qué otra Universidad pública? No son preguntas triviales: algunos espacios ya han abandonado directamente el reclamo de una Universidad pública como horizonte común (Wright y Shore 2017). La Universidad que defendemos es una institución pública amenazada en la actualidad por políticas que disminuyen su financiación y, tal y como hemos señalado más arriba, precarizan de formas diversas a trabajadores y estudiantes. Es, al tiempo, una institución que jerarquiza la producción de conocimiento y tiene serias dificultades para valorar aquel que contribuye a la transformación social entendida en términos que no la reduzcan a la generación de valor para el mercado o la política pública. Así, cuando planteamos otra Universidad pública, una pregunta emerge, una que aún encontramos muy poco en las discusiones sobre precariedad en la academia: ¿Universidad pública para qué y para quién?

\footnotetext{
${ }^{14}$ Sobre las imágenes y su relación con el cambio reflexionamos en un taller en la Escuela de Afuera en marzo de 2016 ( UUn propósito pagano. Taller para reimaginar el cambio social", disponible en: <https://escueladeafuera.net/2016/03/31/un-proposito-pagano-taller-para-reimaginar-elcambio-social/>). El compañero e investigador Amador Fernández-Savater continuó esta reflexión en un texto publicado en eldiario.es en noviembre de 2017 ( A cien años de la revolución rusa, reimaginar el cambio social", disponible en: <http://www.eldiario.es/interferencias/revolucioncambio_social_6_706639343.html>, fecha de acceso: 25 abr. 2018). Según Fernández-Savater, si el filósofo Gilles Deleuze señalaba que "hay imágenes de pensamiento que nos impiden pensar", habría también aimágenes de cambio que nos impiden cambiar, imágenes de lo que supone el cambio que bloquean en la práctica el cambio mismo"; son "ideas preconcebidas (que) organizan nuestra mirada: lo que vemos y lo que no, lo que valoramos y lo que no. Y tienen a la vez una función de orientación: nos ayudan a movernos en lo real, en lo que pasa (o nos desorientan, si no son adecuadas) (...) Entonces, para pensar o cambiar, necesitamos dotarnos en lo posible de otro imaginario: depósitos o semilleros de imágenes que organicen nuestra mirada de otro modo, que nos orienten en sentido diferente. Otras lentes, otras brújulas". Fernández-Savater señala varias imágenes en su texto, entre ellas las que nos da el feminismo, que dibujan una lucha continua y en lo cotidiano, en lugar de una toma del poder única y que lo cambia todo inmediatamente y para siempre.
} 
Caminar hacia una etnografía de la precariedad en la academia nos permitiría identificar cómo las situaciones individuales de precariedad en la Universidad están atravesadas por lógicas estructurales que van más allá del contrato y que requieren de nuestra adherencia en lo cotidiano a formas de regulación que precarizan, tanto a personas - también con contratos indefinidos- como a ciertos tipos de producción de conocimiento, aquellos que no se pliegan del todo a los criterios de valoración imperantes. Mostrar nuestra precariedad e impugnarla requiere pues gobernarse de otra manera, y esto implica al menos dos necesidades: la de contar con apoyos dentro y fuera de la Universidad y la de preguntarse qué otras prácticas queremos que articulen esta institución. Las dos están estrechamente relacionadas con un trabajo por construir, un imaginario y una práctica de la Universidad pública capaz de responder a las necesidades de la gente y no a la autorreproducción de la institución y de las personas que trabajan en ella, tarea en la que podemos echar mano de la crítica institucional y desinstitucionalizadora de la década de 1970 (Basaglia 1972; Ortigosa 1977), de las reflexiones microsociológicas sobre el poder y la Universidad en una suerte de "autoanálisis provocado y acompañado" (Bourdieu, en Castillo y Moré 2017: 10), y de los trabajos sobre precariado cognitivo y su creación de una "función recombinante, de una función de subjetividad capaz de atravesar los varios ámbitos de la producción social, recombinándolos en un marco paradigmático que no dependa del beneficio sino de la utilidad social" (Bifo 2005: 61).

En la actualidad, existen iniciativas que han comenzado a actuar en varios aspectos: las dimensiones laborales de la precariedad, incluyendo factores como la desigualdad de género ${ }^{15}$ (Grupo PrecAnthro dentro de la European Association of Social Anthropologists, EASA; ver Atkins et al. 2018 para EEUU; Federación de Jóvenes Investigadores en España; Grupo de Facebook Precarious Anthropologist en Canadá, entre otras ${ }^{16}$; iniciativas por recuperar la Universidad como centro de producción de conocimiento para todas las personas (Reclaiming our University, plataforma que surgió en la Universidad de Aberdeen) ${ }^{17}$; colectivos que ponen en el centro "construir espacios comunes de diálogo e intercambio" dentro y fuera de la academia, y "acciones tímidas y radicales" en la tarea cotidiana para sustraerse de formas de regulación neoliberales (Red de Estudios de la Ciencia y la Tecnología Red esCTS; Tim-adical Writing Collective 2017) ${ }^{18}$. En todas ellas, la pregunta por los aliados está presente: ¿podemos esperar a que sean las personas con puestos más estables las que tomen la palabra?

Esto es lo que ocurre, por ejemplo, en la iniciativa por recuperar la Universidad

15 Datos de 2017 publicados por Times Higher Education muestran la diferencia de salarios por género en las universidades del Reino Unido. En la mayoría de las universidades de este país, las mujeres académicas, en puestos similares que los hombres, cobran cualitativamente menos: <https://www.timeshighereducation.com/features/times-higher-education-v-c-pay-survey-2017> (Fecha de acceso: 25 abr. 2018). También se puede consultar el reciente trabajo sobre género, universidad neoliberal y feminismo de Taylor y Kinneret (2018).

${ }^{16}$ Ver: <https://www.facebook.com/precanthro/>, <http://precarios.org/Qui\%C3\%A9nes+somos> y <https://www.facebook.com/groups/1750866241866960/>. Fecha de acceso: 25 abr. 2018.

17 Ver: <https://reclaimingouruniversity.wordpress.com/>. Fecha de acceso: 25 abr. 2018.

18 Ver: <https://redescts.wordpress.com/2016/12/06/lost-in-translation-people-technologiespractices-and-concepts-across-boundaries/>. Fecha de acceso: 25 abr. 2018. 
en Aberdeen, tal y como nos explicó el antropólogo y portavoz de la iniciativa Tim Ingold en una entrevista en septiembre de 2016. Este es un ejemplo a examinar para pensar alianzas intra estatus con la potencia de reconfigurar las divisiones laborales que también jerarquizan la producción y valoración de los diferentes tipos de saberes y prácticas en la institución pública. Por un lado, y pensando del lado de los académicos con puestos más estables, cabría apelar a la empatía y la sensibilidad etnográficas que desarrollamos en nuestros lugares de investigación de campo. Por otro, y pensando del lado de los académicos con puestos temporales y precarios, cabría una asunción comprometida con esa reconfiguración de divisiones: la alianza con los estudiantes emergió como natural tanto en el taller de la Escuela de Afuera como en las reflexiones del colectivo de escritura Tim-adical, ambos ya mencionados. La pregunta acerca de la manera en que la precariedad en la academia es similar a la experimentada por otros profesionales, y qué posibilidades para la solidaridad pueden emerger, nos lleva también a reconocer a otros trabajadores precarios en la Universidad, precisamente aquellos que sostienen el trabajo académico: personal de administración, biblioteca, cafetería, limpieza y mantenimiento, cuyos puestos, cada vez más, están externalizados a empresas privadas y no disfrutan de los beneficios laborales del personal empleado directamente por la Universidad ${ }^{19}$. El nuevo imaginario que nos permite pensar la lucha contra la precariedad no está compuesto de imágenes de académicos solos compitiendo en la pelea, sino de un colectivo diverso que, sin embargo, se parece más a aquello que sostiene la Universidad como institución pública de todas y para todas.

\section{AGRADECIMIENTOS}

Queremos dar las gracias a nuestros estudiantes, a las personas con las que hemos compartido el trabajo de campo y a las compañeras dentro y fuera de la Universidad con las que hemos colaborado en espacios de producción de conocimiento. Queremos destacar nuestro agradecimiento al colectivo Escuela de Afuera, que acogió el taller sobre precariedad en la academia en el verano de 2017; a todos aquellos que respondieron nuestras preguntas durante ese año, y también a los que nos explicaron que no podían, precisamente por la cantidad de tareas acumuladas y el poco tiempo para acometerlas; y a la EASA y las compañeras de PrecAnthro, por invitarnos a compartir nuestras reflexiones en el seminario On Politics and Precarities in Academia: Anthropological Perspectives, que tuvo lugar en la Universidad de Berna (Suiza), en noviembre de 2017. Gracias especiales también a todas las autoras que han contribuido a este número, a Kristin DeGeorge por la traducción, a Irene Rodríguez Newey, Jessica Sklair y Daniel Amelang por la ayuda en la edición, a Ernesto García López por el diseño de la portada, a las revisoras anónimas por sus comentarios y a los editores de la revista.

\footnotetext{
${ }^{19}$ Conviene destacar que la plataforma de la Universidad de Aberdeen sí tiene en cuenta estas alianzas.
} 


\section{ANEXO}

En la versión en línea de este artículo se encuentra disponible su traducción al inglés.

\section{BIBLIOGRAFÍA CITADA}

AllegraLab. 2016. "University Crisis" [Thematic Thread]. AllegraLaboratory. Disponible en: <http:// allegralaboratory.net/tag/university crisis/>. Fecha de acceso: 8 dic. 2016.

Atkings, Celeste, Louis E. Esparza, Ruth Milkman y Catherine L. Moran. 2018. "Organizing the Academic Precariat in the United States". Global Labour Journal 9(1): 76-81.

Ávila, Débora y Marta Malo [del Observatorio Metropolitano]. 2008. "Diferencias gobernadas, nuevos racismos". Periódico Diagonal 4 sept. Disponible en: <https://www.diagonalperiodico.net/la plaza/diferencias gobernadas nuevos racismos.html>. Fecha de acceso: 14 feb. 2018.

Basaglia, Franco. 1972. "La Utopía de la Realidad”. Disponible en: <http://www.triestesalutementale.it/ spagnolo/basaglia_1972_lautopiadelarealidad.pdf $>$. Fecha de acceso: 14 feb. 2018.

Bifo, Franco Berardi. 2005. Almas al trabajo. Alienación, extrañamiento, autonomía. Madrid: Enclave de Libros.

Brown, Wendy. 2015. Undoing the Demos: Neoliberalism's Stealth Revolution. Nueva York: Zone Books.

Butler, Judith. 2001. "What is critique? An Essay on Foucault's Virtue". Disponible en: <http://eipcp.net/ transversal/0806/butler/en>. Fecha de acceso: 13 jul. 2015.

Butler, Nick, Helen Delaney y Martyna Sliwa. 2017. "The Labour of Academia”. ephemera 17(3): 467-480.

Castillo, Juan José y Paloma Moré. 2017. "La Universidad sin futuro. Precariedad e incertidumbre del trabajo universitario". Disponible en <https://www.ucm.es/data/cont/docs/1030-2017-05-18la\%20universidad\%20sin\%20futuro.pdf>. Fecha de acceso: 14 feb. 2018.

Cultural Anthropology. 2018. "Academic Precarity in American Anthropology: A Forum". Dialogues, Cultural Anthropology website. Disponible en: <https://culanth.org/fieldsights/1321-academicprecarity-in-american-anthropology-a-forum>. Fecha de acceso: 12 feb. 2018.

Foucault, Michel. 1997. "What is Critique?", en Sylvère Lothringer y Lysa Hochroth (eds.), The Politics of Truth: 23-82. Nueva York: Semiotexte.

Gallas, Alexander. 2018. "Introduction. The Proliferation of Precarious Labour in Academia". Global Labour Journal 9(1): 69-75.

Gill, Rosalind. 2010. "Breaking the Silence: The Hidden Injuries of Neo-liberal Academia", en Róisín Ryan Flood y Rosalind Gill (eds.), Secrecy and Silence in the Research Process: Feminist Reflections: 228-244. Londres: Routledge.

Haraway, Donna J. 1995. Ciencia, cyborgs, y mujeres. La invención de la naturaleza. Madrid: Cátedra.

Heatherington, Tracey y Filippo M. Zerilli. 2017. "Anthropologists Witnessing and Reshaping the neoliberal Academy". Anuac 6(1): 23-98.

Hernández, Fernando, Juana María Sancho, Amalia Creus y Alejandra Montané. 2010. "Becoming University Scholars: Inside Professional Autoethnographies". Journal of Research Practices 6(1), Article M7. Disponible en: <http://jrp.icaap.org/index.php/jrp/article/view/204/188>. Fecha de acceso: 14 feb. 2018.

Indocentia. 2015. “Disciplinar la investigación, devaluar la docencia: cuando la Universidad se vuelve empresa". eldiario.es. Por Amador Fernández Savater. Disponible en: < https://www.eldiario.es/ interferencias/Disciplinar investigacion devaluar docencia Universidad_6_486161402.html>. Fecha de acceso: 20 dic. 2017

Laval, Christian y Pierre Dardot. 2013. La nueva razón del mundo. Ensayo sobre la sociedad neoliberal. Barcelona: Gedisa.

Lorey, Isabell. 2016. Estado de inseguridad: Gobernar la precariedad. Madrid: Traficantes de Sueños. Malo de Molina, Marta. 2004. "Prólogo", en Posse, Derive Aprodi, Precarias a la deriva, Grupo 116, Colectivo Sin Ticket, Colectivo Situaciones et al., Nociones Comunes: experiencias y ensayos entre investigación y militancia: 13-39. Madrid: Traficantes de Sueños. 
Mckenna, Brian. 2016. "Class Struggle is the Name of the Game at Universities. It's the Ethical Elephant in the Room". AAA Ethics Blog 28 jun. Disponible en: <http://ethics.americananthro.org/class struggle is the name of the game at universities its the ethical elephant in the room/ $>$. Fecha de acceso: 14 feb. 2018.

Muehlebach, Andrea. 2013. "On Precariousness and the Ethical Imagination: The Year 2012 in Sociocultural Anthropology". American Anthropologist 115(2): 297-311.

Ortigosa, Juan C. 1977. El análisis institucional (por un cambio de las instituciones). Madrid: Campo Abierto Ediciones S.A.

Peacock, Vita. 2016. "Academic Precarity as Hierarchical Dependency in the Max Planck Society". HAU: Journal of Ethnographic Theory 6(1): 95-119.

Pérez, Marta y Ainhoa Montoya. 2016. "Unravelling Academic Precarity”. AllegraLaboratory. \#UniversityCrisis Thematic Thread. Disponible en: <http://allegralaboratory.net/unravelling academic precarity universitycrisis/>. Fecha de acceso: 8 dic. 2016.

Strathern, Marilyn (ed.). 2000. Audit Cultures. Antbropological Studies in Accountability, Ethics and the Academy. Londres: Routledge.

Taylor, Yvette y Kinneret Lahad. 2018. Feeling Academic in the Neoliberal University: Feminist Flights, Fights and Failures. Basingstoke, Hampshire: Palgrave MacMillan.

Tim-adical Writing Collective. 2017. "Vulnerabilities, Complicities, and Injustices: "Tim-adical” Actions for Change in the Neoliberal Academy". ephemera 17(3): 691-704.

Thorkelson, Eli. 2016. "Precarity Outside: The Political Unconciousness of French Academic Labor". American Ethnologist 43(3): 475-488.

Wright, Susan y Chris Shore. 2017. Death of the Public University? Uncertain Futures for Higher Education in the Knowledge Economy. Nueva York: Berghahn.

Zafra, Remedios. 2017. El Entusiasmo. Barcelona: Anagrama. 